䓍

SSCL-638

August 1993

Distribution Category: $\mathbf{4 0 0}$

C.-M. Kwan

K. Yeung

L.K. Mestha

\title{
Determination of Optimal Gains for Constrained Controllers
}

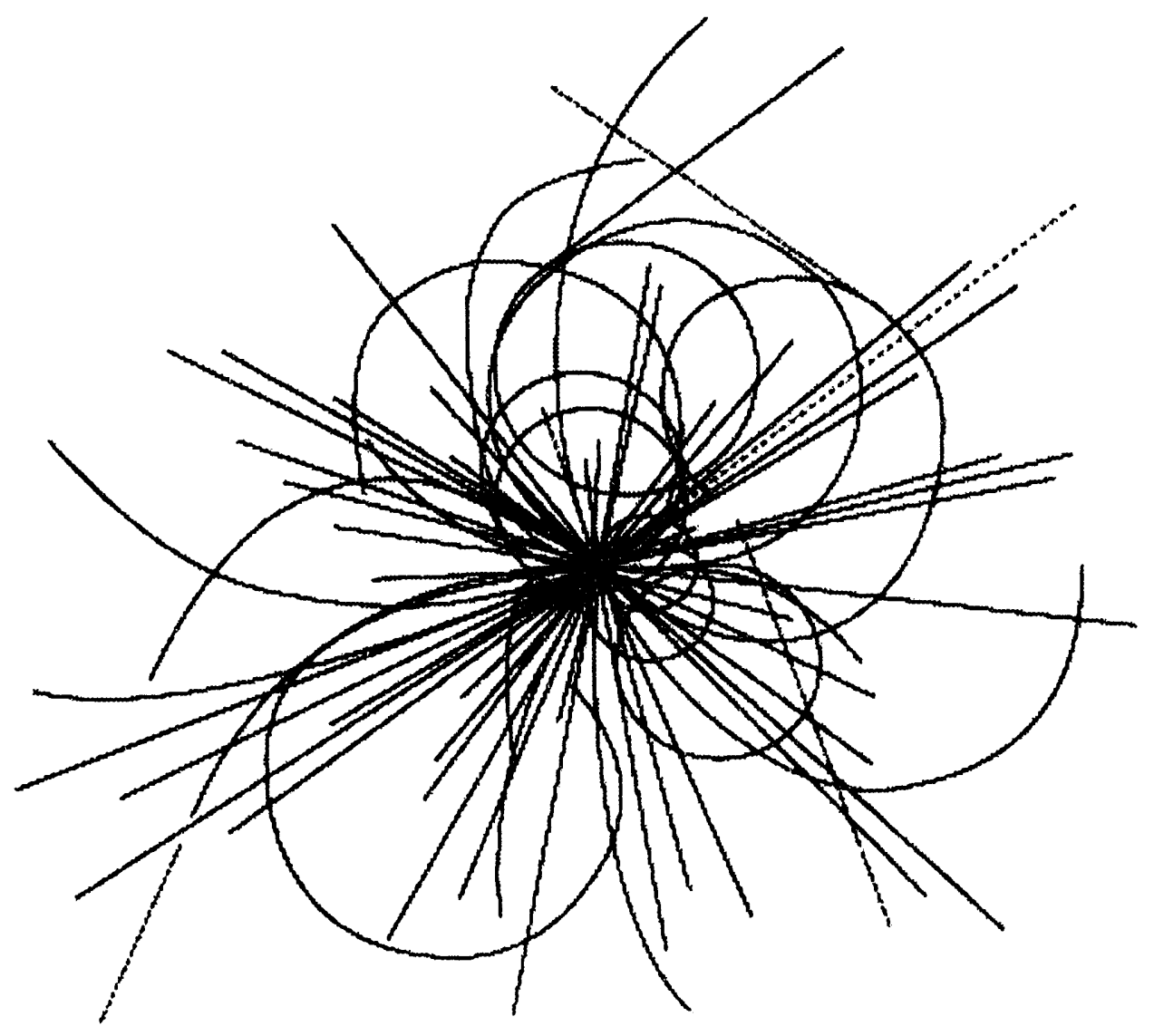

\section{Superconducting Super Collider Laboratory}




\section{Disclaimer Notice}

This report was prepared as an scoount of work eponsored by an agency of the United States Govemment. Nelther the United States Government of any agency thereol, nor any of their employess, makes any warranty, express or implied, or assumes any legal liability or responaibility for the accuracy, completeness, or uselutness of any information, apparatus, product, or process dieclosed, or represents that hs use would nol infringe privately owned rights. Relerence herein to any spectic commercial product, process, or service by trade name, trademark, manufacturer, or otherwise, dops nol necsessarlly consthute or imply tis endorsement, recommendation, or favoring by the United States Government or any agency thereof. The viows and opinions of authors expresead herein do not necesearly state or reflect those of the United States Government or any agency thereot.

Superconducting Super Collider Laboratory is an equal opportunity employer. 
SSCL-638

\title{
Determination of Optimal Gains for Constrained Controllers
}

\author{
C.-M. Kwan and L.K. Mestha \\ Superconducting Super Collider Laboratory* \\ 2550 Beckleymeade Ave. \\ Dallas, TX 75237 \\ K. Yeung \\ Department of Electrical Engineering \\ The University of Texas at Arlington \\ Arlington, TX 76019
}

August 1993

*Operated by the Universities Research Association, Inc., for the U.S. Department of Energy under Contract No. DE-AC35-89ER40486.

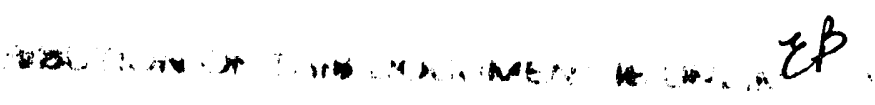




\title{
Determin tion of Optimal Gains for Co' istrained Controllers
}

\author{
C.-M. Kwan, K. Yeung and L.K. Mestha
}

\begin{abstract}
In this report, we consider the determination of optimal gains, with respect to a certain performance index, for state feedback controllers where some elements in the gain matrix are constrained to be zero. Two iterative schemes for systematically finding the constrained gain matrix are presented. An example is included to demonstrate the procedures.
\end{abstract}




\subsection{INTRODUCTION}

Consider the regulation of the following system (tracking can be treated similarly):

$$
\dot{\mathbf{x}}=\mathbf{A x}+\mathbf{B u},
$$

$\mathbf{x}$ is in $\mathbf{R}^{\mathrm{n}}, \mathbf{u}$ is in $\mathbf{R}^{\mathrm{m}}, \mathbf{A}$ is in $\mathbf{R}^{\mathrm{n} \times \mathbf{n}}$, and $\mathbf{B}$ is in $\mathbf{R}^{\mathrm{n} \times m}$.

State feedback controller of the form

$$
\mathbf{u}=-\mathbf{K x}
$$

is used with the structure of $K$ already fixed in some ways. For example, $K$ may be in the form of diag $\left\{k_{1}, \mathbf{k}_{2}\right\}$ for a 2-input 2-state system, i.e, some elements of $\mathbf{K}$ are constrained to be zero. This is not uncommon in many industrial control systems. For example, in accelerator physics, ${ }^{1}$ people have intuitively assumed that all loops are decoupled. The resulting controller is usually in a form where the gain matrix is almost diagonal. ${ }^{1}$ Some fine tunings on the gains by the trial-and-error method are applied to further improve the response. Then the controller is implemented by hardware. Once the hardware is implemented and the system starts to work, people are highly reluctant to change the controller. Under this situation, can we improve the system performance even further with respect to some performance indices such as the one shown below?

$$
J=\frac{1}{2} \int_{0}^{\infty} \mathbf{x}^{\mathrm{T}} \mathbf{Q} \mathbf{x}+\mathbf{u}^{\mathrm{T}} \mathbf{R} \mathbf{u d t} \quad \mathbf{R}>0, \quad \mathbf{Q} \geq 0 .
$$

The answer is positive even though the optimal gains may not always exist.

\subsection{MAIN RESULT}

Substituting Eq. (2) into (1) yields

$$
\mathbf{x}(t)=\Phi(t, 0) \mathbf{x}(0)
$$

where

$$
\Phi(t, 0)=\exp [(\mathbf{A}-\mathbf{B K}) t]
$$

and $\mathbf{K}$ is some unspecified constrained gain matrix.

Using Eqs. (2) and (4) into Eq. (3) gives

$$
\mathrm{J}=\frac{1}{2} \mathbf{x}_{0}^{\mathrm{T}} \int_{0}^{\infty} \Phi^{\mathrm{T}}(\mathrm{t}, 0)\left[\mathbf{Q}+\mathbf{K}^{\mathrm{T}} \mathbf{R K}\right] \Phi(\mathrm{t}, 0) \mathrm{dt} \mathbf{x}_{0} .
$$

To eliminate the dependence of optimal control on $\mathbf{x}(0)$, a simple way is by assuming that $\mathbf{x}(0)$ is a random variable uniformly distributed on the surface of the $n$-dimensional unit sphere. ${ }^{2-4}$ i.e,

$$
\mathrm{E}\left\{\mathbf{x}_{0} \mathbf{x}_{0}{ }^{\mathrm{T}}\right\}=\mathbf{I} / \mathbf{n}
$$


Taking the expectation on Eq. (5) and using Eq. (6) yields

$$
J_{m}=\frac{1}{2 n} \int_{0}^{\infty} \operatorname{trace}\left[\Phi^{T}(t, 0)\left[Q+K^{T} R K\right] \Phi(t, 0)\right] d t
$$

Remark 1: As pointed out by Levine et al., ${ }^{2}$ the modified performance criterion in Eq. (7) has the following properties:

- Retains many properties of linear systems which are optimal with respect to standard quadratic criterion

- The design is optimal in an average sense (note the division by $n$ in Eq. (7))

- Obtains an upper bound on the worst case performance.

For detailed explanations of these properties, see Reference 1.

Now we present two algorithms for determining $\mathbf{K}$. Both algorithms can be easily implemented with about 10 lines of MATLAB commands. They can be readily applied to systematically optimize any practical systems with constrained controllers.

Algorithm 1: (Riccati equation approach)

1. Find $\mathbf{K}_{(0)}$ such that $\left(\mathbf{A}-\mathbf{B} \mathbf{K}_{(0)}\right)$ is asymptotically stable.

2. Solve $\mathbf{P}_{(\mathrm{i})}$ from

$$
\mathbf{P}_{(\mathrm{i})}\left(\mathbf{A}-\mathbf{B} \mathbf{K}_{(\mathrm{i})}\right)+\left(\mathbf{A}-\mathbf{B K} \mathbf{K}_{(\mathrm{i})}\right)^{\mathrm{T}} \mathbf{P}_{(\mathrm{i})}+\mathbf{Q}+\mathbf{K}_{(\mathrm{i})}^{\mathrm{T}} \mathbf{R} \mathbf{K}_{(\mathrm{i})}=0 .
$$

3. $\mathbf{K}_{(\mathrm{i})}=-\mathbf{R}^{-1} \mathbf{B}^{\mathbf{T}} \mathbf{P}_{(\mathrm{i})}$.

4. Set those elements of $\mathbf{K}_{(\mathrm{i})}$ to zero in order to comply with the constraints imposed on $\mathbf{K}$. If (A BK $\left._{(i)}\right)$ is asymptotically stable, then $\mathrm{i}=\mathrm{i}+1$ and go to 2 ; else the algorithm fails.

5. $\mathbf{K}=\lim \mathbf{K}_{(\mathrm{i})}, \mathrm{J}_{\mathrm{m}}=\lim \left\{\operatorname{trace}\left(\mathbf{P}_{(\mathrm{i})}\right) / \mathrm{n}\right\}$ as $\mathrm{i}$ tends to infinity.

Algorithm 2: (Gradient search approach)

After some lengthy but quite straightforward derivations, it can be shown that the gradient of $J_{m}$ in Eq. (7) is given by

$$
\frac{\partial J_{m}}{\partial \mathbf{K}}=\left(\mathbf{R K}-\mathbf{B}^{\mathrm{T}} \mathbf{P}\right) \mathbf{M}
$$

where $\mathbf{P}, \mathbf{M}$ satisfy

$$
\begin{gathered}
\mathbf{P}(\mathbf{A}-\mathbf{B K})+(\mathbf{A}-\mathbf{B K})^{\mathrm{T}} \mathbf{P}+\mathbf{Q}+\mathbf{K}^{\mathrm{T}} \mathbf{R K}=0 \\
\mathbf{M}(\mathbf{A}-\mathbf{B K})^{\mathbf{T}}+(\mathbf{A}-\mathbf{B K}) \mathbf{M}+\mathbf{I}=0 .
\end{gathered}
$$


1. Find $\mathbf{K}_{(0)}$ such that $\left(\mathbf{A}-\mathbf{B} \mathbf{K}_{(0)}\right)$ is asymptotically stable.

2. Adjust those nonzero elements of $\mathbf{K}_{(\mathrm{i})}$ according to

$$
\begin{aligned}
& \quad \mathbf{K}_{(\mathrm{i})}=\mathbf{K}_{(\mathrm{i}-1)}-\mu \frac{\partial \mathrm{J}_{\mathrm{m}}}{\partial \mathbf{K}}, \\
& \mu>0 \text { and } \frac{\partial \mathrm{J}_{\mathrm{m}}}{\partial \mathbf{K}}=\left(\mathbf{R} \mathbf{K}_{(\mathrm{i}-1)}-\mathbf{B}^{\mathrm{T}} \mathbf{P}_{(\mathrm{i}-1)}\right) \mathbf{M}_{\mathrm{i}-1} . \\
& \mathbf{P}_{(\mathrm{i}-1)} \text { and } \mathbf{M}_{(\mathrm{i}-1)} \text { are the solutions of } \\
& \mathbf{P}_{(\mathrm{i}-1)}\left(\mathbf{A}-\mathbf{B} \mathbf{K}_{(\mathrm{i}-1)}\right)+\left(\mathbf{A}-\mathbf{B} \mathbf{K}_{(\mathrm{i}-1)}\right)^{\mathrm{T}} \mathbf{P}_{(\mathrm{i}-1)}+\mathbf{Q}+\mathbf{K}_{(\mathrm{i}-1)}^{\mathrm{T}} \mathbf{R} \mathbf{K}_{(\mathrm{i}-1)}=0, \\
& \mathbf{M}_{(\mathrm{i}-1)}\left(\mathbf{A}-\mathbf{B} \mathbf{K}_{(\mathrm{i}-1)}\right) \mathbf{T}+\left(\mathbf{A}-\mathbf{B} \mathbf{K}_{(\mathrm{i}-1)}\right) \mathbf{M}_{(\mathrm{i}-1)}+\mathbf{I}=0 .
\end{aligned}
$$

3. If $\left(\mathbf{A}-\mathbf{B K} \mathbf{K}_{(i)}\right)$ is asymptotically stable then $i=i+1$ and go to 2 ; else the algorithm fails.

4. $\mathbf{K}=\lim \mathbf{K}_{(\mathrm{i})}, \mathrm{J}_{\mathrm{m}}=\lim \left\{\operatorname{trace}\left(\mathbf{P}_{(\mathrm{i})}\right) / \mathrm{n}\right\}$ as $\mathrm{i}$ tends to infinity.

Remark 2: It is assumed in this report that there exists a $\mathbf{K}$ with constrained elements such that $(\mathbf{A}-\mathbf{B K})$ is asymptotically stable. Non-existence of $\mathbf{K}$ would imply $\mathbf{J}_{\mathrm{m}}$ in Eq. (7) goes unbounded and hence the performance index is meaningless.

Remark 3: Similar to the optimal output feedback control, ${ }^{1,2}$ there is no guarantee that the two procedures above will converge to the optimal solution. However, it is worth to try these systematic procedures because system performance may be improved significantly with a slight change of gains (possibly by changing some resistor and/or capacitor values). This is especially true for large scale systems where adjusting gains by trial-and-error is almost impossible.

\subsection{EXAMPLE}

Consider the system described in Eq. (1) with

$$
\mathbf{A}=\left[\begin{array}{rrr}
0 & 1 & 0 \\
0 & 0 & 1 \\
0 & -1 & -2
\end{array}\right] \quad \mathbf{B}=\left[\begin{array}{ll}
1 & 0 \\
0 & 1 \\
1 & 0
\end{array}\right]
$$

We assumed the gain matrix in Eq. (2) is of the form

$$
\mathbf{K}=\left[\begin{array}{ccc}
\mathbf{k}_{11} & 0 & \mathbf{k}_{13} \\
0 & \mathbf{k}_{22} & 0
\end{array}\right]
$$

$\mathbf{Q}$ and $\mathbf{R}$ in Eq. (3) are selected to be $\mathbf{I}_{3 \times 3}$ and $I_{2 \times 2}$, respectively.

When there are no constraints on $\mathbf{K}$, the optimal performance $J_{m}$ can be calculated as 0.7541 . The initial values of $k_{11}, k_{22}$ and $k_{13}$ are chosen to be $0.926,1.0357$ and 0.3161 , respectively. By using Algorithm $1, J_{m}$ converges after 5 iterations and equals to $0.819 ; \mathrm{k}_{11}, \mathrm{k}_{22}$ and $\mathrm{k}_{13}$ are $1,1.1448$ and 0.336 , respectively. By choosing $\mu=0.5$, Algorithm 2 converges after 10 iterations and yields $a J_{m}$ of 0.8179 . The values of $k_{11}, k_{22}$ and $\mathrm{k}_{13}$ are $1.0522,1.1759$ and 0.3105 , respectively. It appears that Algorithm 2 is slightly better than Algorithm 1 in this example in the sense that the value of $J_{m}$ is closer to the optimal unconstrained $J_{m}$. 


\section{REFERENCES}

1. B. D. O. Anderson, and J. B. Moore, Linear Optimal Control, Prentice-Hall, (1971).

2. W. S. Levine, and M. Athans, "On the Determination of the Optimal Constant Output Feedback Gains for Linear Multivariable Systems," IEEE Trans. On Autom. Contr., 15, pp. 44-48, (1970).

3. D. L. Kleinman, T. Fortmann, and M. Athans, "On the Design of Linear Systems with Piecewise-Constant Feedback Gains," IEEE Trans. On Autom. Contr., 13, pp. 354-361, (1968).

4. D. L. Kleinman, and M. Athans, "The Design of Suboptimal Linear Time-Varying Systems," IEEE Trans. On Autom. Contr., 13, pp. 150-159, (1968).

5. L. K. Mestha, "Beam Control Feedback Loops for the Low Energy Booster," Superconducting Super Collider Laboratory, Technical Repon SSCL-559, (1991). 

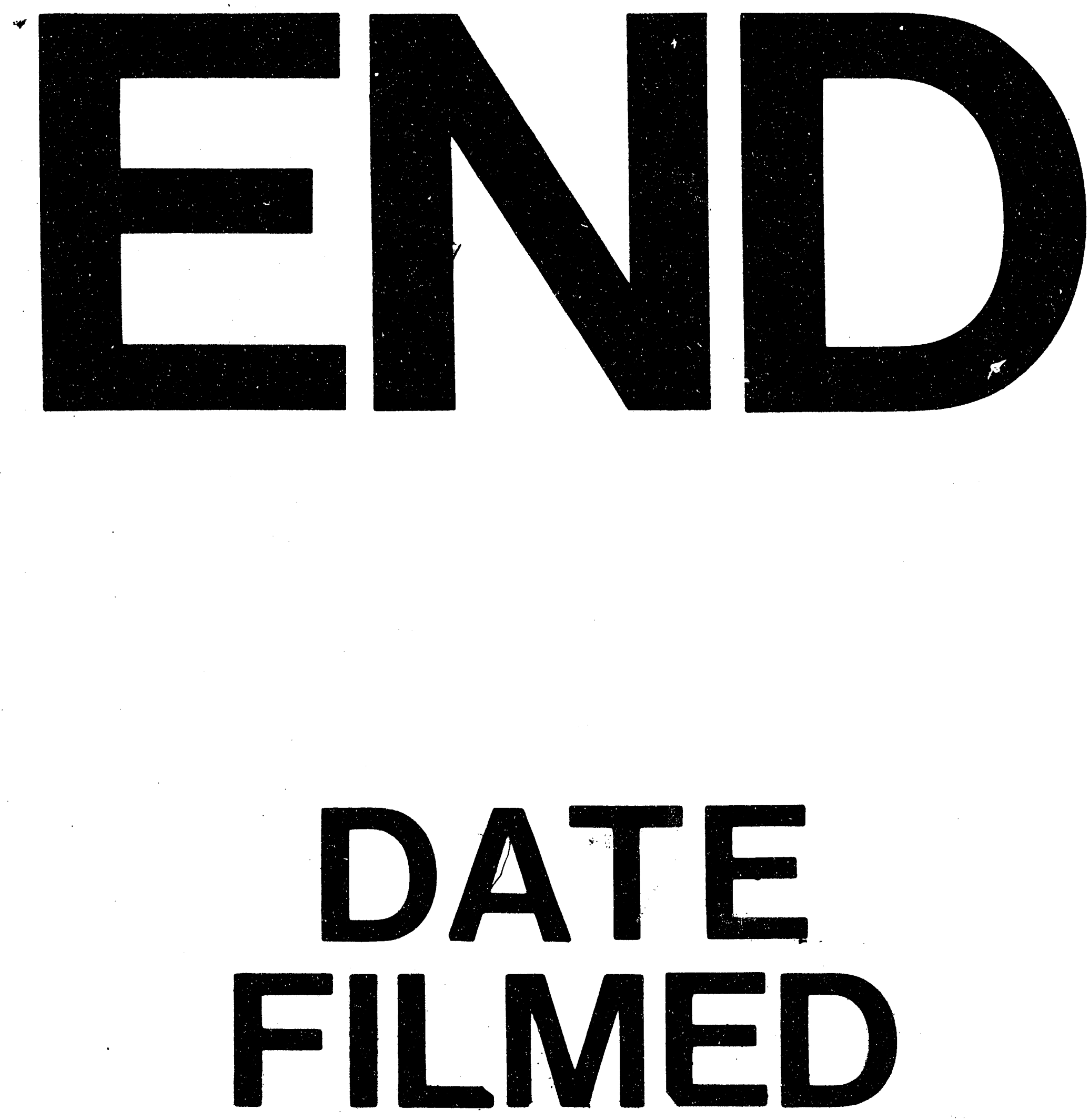

1

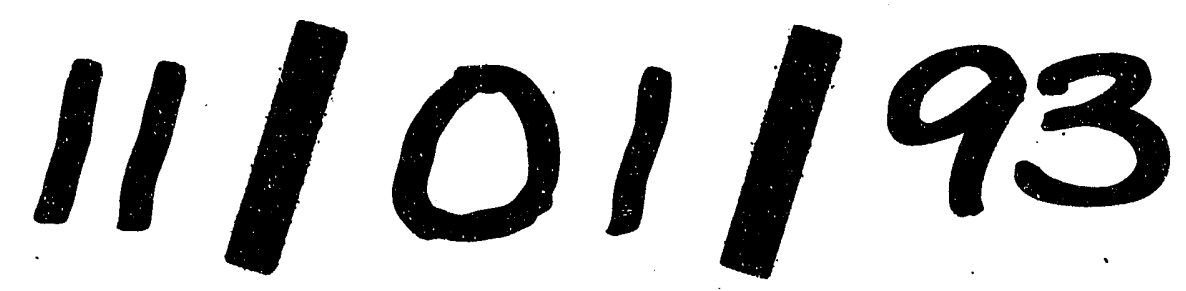


